\title{
Mineral Scale Prevention on Electrically Conducting Membrane Distillation Membranes using Induced Electrophoretic Mixing
}

\author{
Unnati Rao ${ }^{a}$, Arpita Iddya ${ }^{a}$, Bongyeon Jung ${ }^{a}$, Chia Miang Khor ${ }^{a}$, Craig Turchi ${ }^{b}$, Tzahi Cath ${ }^{c}$, Zachary \\ Hendren $^{d}$, Eric M.V. Hoek ${ }^{a}$, Guy Z. Ramon ${ }^{e}$, David Jassby*,a \\ aDepartment of Civil and Environmental Engineering, University of California, Los \\ Angeles, CA 90095-153, USA \\ ${ }^{\mathrm{b}}$ National Renewable Energy Lab, Department of Energy, Golden, Colorado 80401,
} United States

'Department of Civil and Environmental Engineering, Colorado School of Mines, Golden, Colorado 80401, United States

${ }^{d} R T I$ International - Energy Technology Division, 3040 Cornwallis Rd, Research Triangle Park, NC 27709
eDepartment of Civil and Environmental Engineering, Technion-Israel Institute of Technology, Haifa, 32000, Israel

* Corresponding Author, jassby@ucla.edu

Submitted for Potential Publication in

Environmental Science \& Technology 


\section{Supporting information}

Table S1: Calcium sulfate scaling solution recipe

\begin{tabular}{|ll|}
\hline Salt & Concentration (mM) \\
\hline $\mathrm{Na}_{2} \mathrm{SO}_{4}$ & 10.500 \\
\hline $\mathrm{MgSO}_{4}$ & 14.500 \\
\hline $\mathrm{CaCl}_{2}$ & 16.400 \\
\hline $\mathrm{pH}$ & 6.9 \\
\hline
\end{tabular}

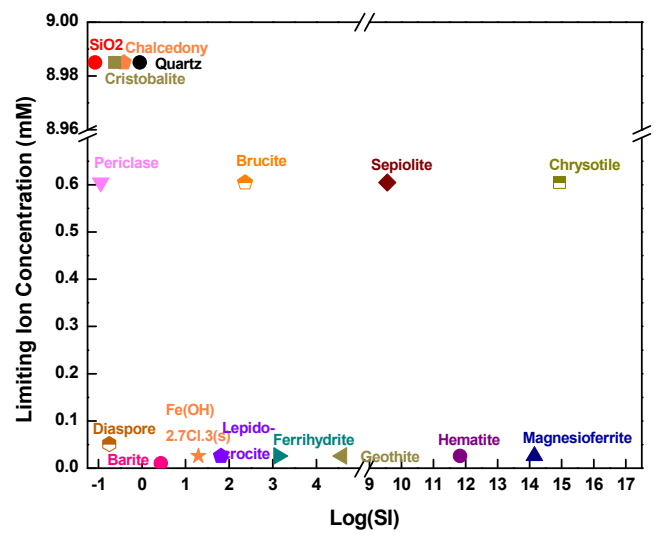

Table S2: Silicate scaling solution recipe

\begin{tabular}{|ll}
\hline Salt & Concentration (mM) \\
\hline $\mathrm{Na}_{2} \mathrm{SiO}_{3}, 5 \mathrm{H}_{2} \mathrm{O}$ & 8.985 \\
$\mathrm{AlCl}_{3}, 6 \mathrm{H}_{2} \mathrm{O}$ & 0.051 \\
\hline $\mathrm{BaCl}_{2}, 2 \mathrm{H}_{2} \mathrm{O}$ & 0.010 \\
\hline $\mathrm{FeCl}_{3}, 6 \mathrm{H}_{2} \mathrm{O}$ & 0.026 \\
$\mathrm{CaCl}_{2}, 2 \mathrm{H}_{2} \mathrm{O}$ & 1.439 \\
\hline $\mathrm{KCl}$ & 1.372 \\
\hline $\mathrm{MgCl}_{2}, 6 \mathrm{H}_{2} \mathrm{O}$ & 0.605 \\
\hline $\mathrm{Na}_{2} \mathrm{SO}_{4}$ & 0.774 \\
\hline $\mathrm{pH}$ & 10 \\
\hline
\end{tabular}

Figure S1: Saturation indices of minerals that could potentially precipitate in the feed during the desalination of silicate solution. 


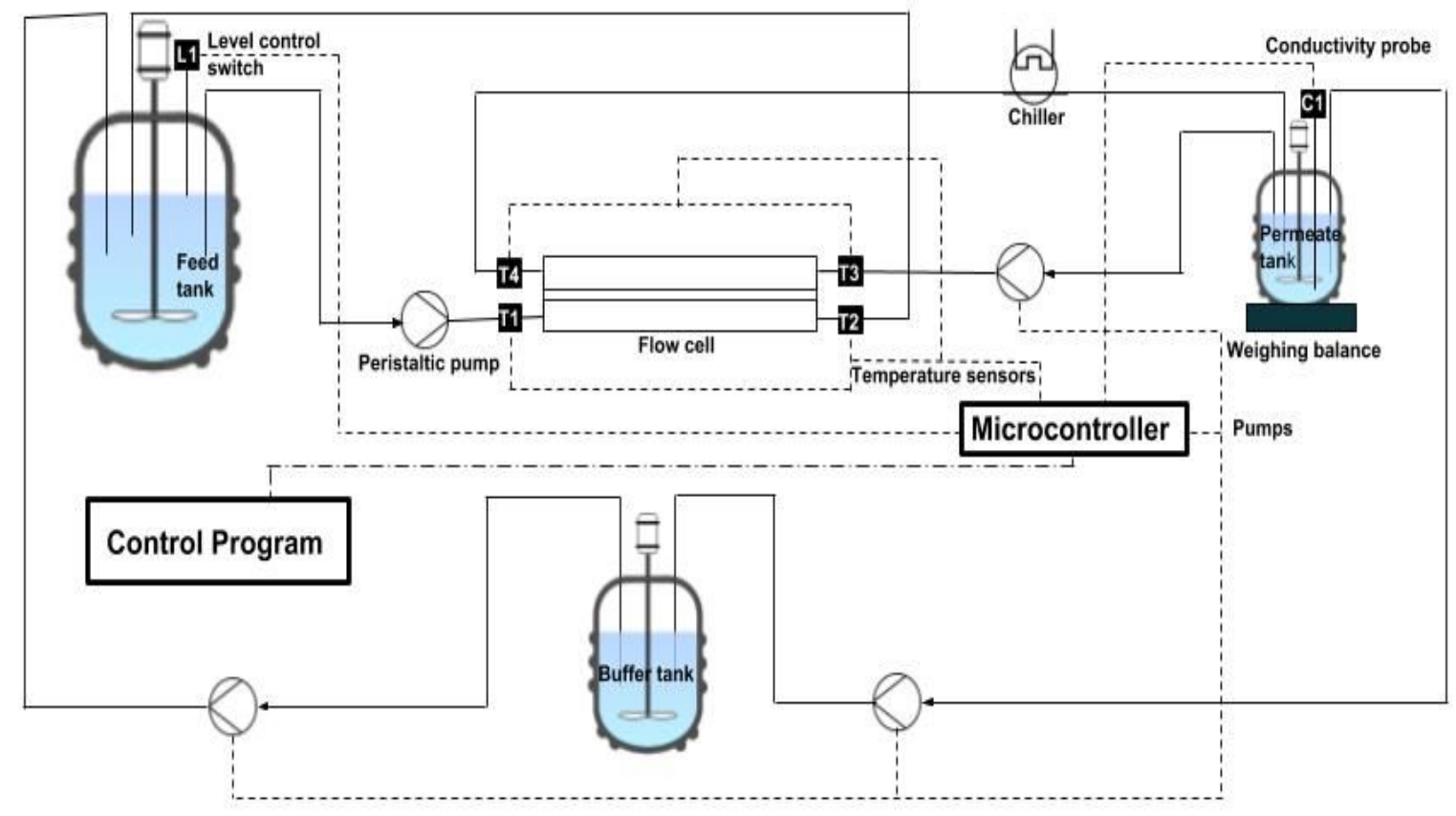

Figure S2: System process diagram
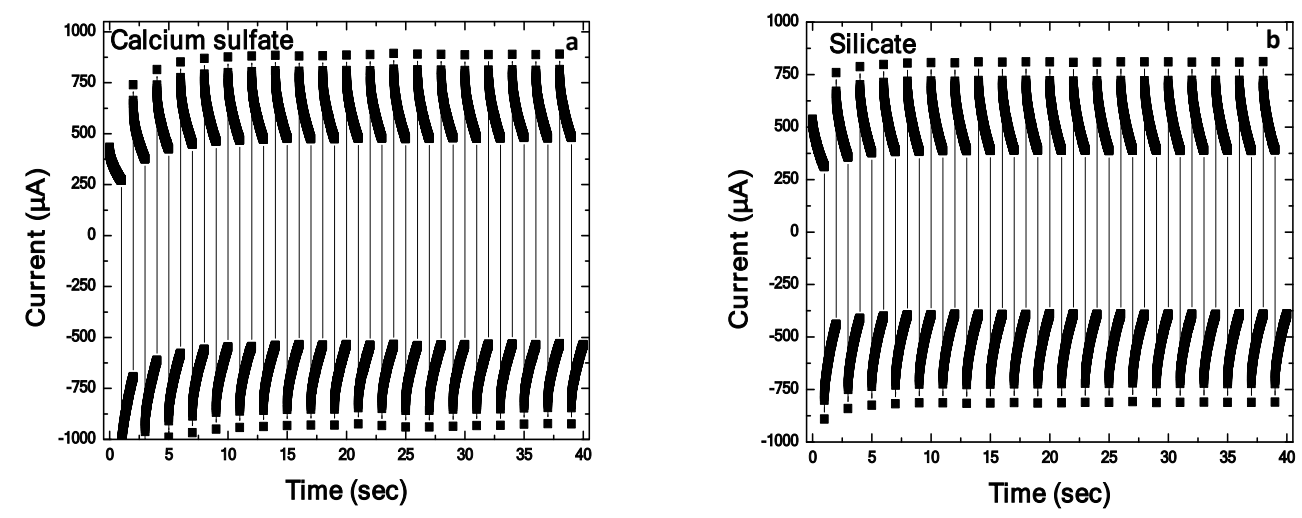

Figure S3. Chronoamperometry curves with CNT membrane and metal plate (Pt-Ti) as electrodes for (a) $\mathrm{CaSO}_{4}$, and (b) silicate solution.

\section{Calculation of saturation index along the membrane surface ${ }^{[1]}$}

$c_{m}=c_{b} * \exp (J / \rho K) \quad$ Equation $\mathrm{S1}$

Where, $c_{m}$ is the salt concentration at the membrane surface, $c_{b}$ the salt concentration in the bulk, J the flux of water across the membrane, $\rho$ the density of water, and $K$ the solute mass transfer coefficient. The solute mass transfer coefficient can be calculated using the Graetz-Leveque mass transfer analogy: 
$S h=1.86\left(\operatorname{Re} * S c * \frac{d_{h}}{L}\right)^{0.33}$

Equation S2

where $\mathrm{L}$ is the length of the channel, $d_{h}$ is the hydraulic diameter, and Sh and Sc are Sherwood and Schmidt numbers respectively, which can be calculated using:

$S h=\frac{K * d_{h}}{D}$

Equation S3

$S c=\frac{\mu}{\rho * D}$

Equation 54

where $\mu$ is the viscosity of water, and $\mathrm{D}$ the diffusion coefficient of the solute.

The flux $(\mathrm{J})$ in equation 2 is calculated by iteratively solving for the membrane surface temperatures on the feed and permeate side using eq. 7-15. Temperature difference in MD system leads to heat transfer from the hot feed to cold permeate. In addition to heat transfer, vaporization of water at the feed side leads to a further decline in temperature due to loss of latent heat. To account for the polarization effect, we assume steady state conditions with heat transfer $(Q)$ in the bulk of the feed and permeate to be equal to the heat transferred across the membrane:

$Q=h_{f}\left(T_{b f}-T_{c}\right)=h_{c}\left(T_{c}-T_{m p}\right)+J \lambda=h_{m}\left(T_{m f}-T_{m p}\right)=h_{p}\left(T_{m p}-T_{b p}\right) \quad$ Equation S5

$T_{m p}=T_{b p}+\frac{\left(T_{b f}-T_{b p}\right)}{h_{p}}\left[\frac{1}{\left(1 / h_{m}\right)+\left(1 /\left(h_{c}+h_{v}\right)\right)+\left(1 / h_{f}\right)+\left(1 / h_{p}\right)}\right]$

Equation S6

$T_{c}=T_{b f}-\frac{\left(T_{b f}-T_{b p}\right)}{h_{f}}\left[\frac{1}{\left(1 / h_{m}\right)+\left(1 /\left(h_{c}+h_{v}\right)\right)+\left(1 / h_{f}\right)+\left(1 / h_{p}\right)}\right]$

Equation 57

where $T_{b p}$ and $T_{b f}$ are the bulk permeate and feed temperatures respectively, $T_{c}, T_{m f}, T_{m p}$ are the temperatures of the CNT surface, PP membrane surface, and PP back side (i.e., permeate side), and $h_{f}$, $h_{p}, h_{m}, h_{v}$, and $h_{c}$ are the heat transfer coefficients on the feed side, permeate side, membrane, vapor and the CNT layer respectively (calculated from equations 9-15). $h_{f}$ and $h_{p}$ are calculated using the Nusselt equation:

$h_{x}=\frac{N u_{x} k_{x}}{d_{h}} \quad$ Equation $\mathrm{S} 8$

where, $k_{x}$ is the fluid thermal conductivity.

$N u_{x}$ in equation 9 is the Nusselt number, obtained using the equation:

$N u=1.86\left(\operatorname{Re} \operatorname{Pr} \frac{d_{h}}{L}\right)^{0.33} \quad$ Equation 59

Where, Reynolds number, $R e=\frac{d_{h} v \rho}{\mu} \quad$ Equation $S 10$

And PrandtI number, $\operatorname{Pr}=\frac{c_{p} \mu}{k} \quad$ Equation $S 11$

where $v$ is the velocity, $\mathrm{c}_{\mathrm{p}}$ is the specific heat capacity, and $\mathrm{k}$ is the thermal conductivity of the fluid.

$h_{m}, h_{v}$, and $h_{c}$ are determined as: 
$h_{m}=\frac{k_{m}}{\delta_{m}}$

$h_{v}=\frac{J \lambda}{T_{c}-T_{m p}}$

$h_{c}=\frac{k_{c}}{\delta_{c}}$
Equation S12

Equation $\mathrm{S13}$

Where, $k_{m}, k_{c}$ and $\delta_{m}, \delta_{c}$ are the thermal conductivity and thickness of membrane and the CNT layer respectively, and $\lambda$ is the latent heat of vaporization.

\section{Modeling surface $\mathrm{pH}$ under the influence of applied potential}

Equation S15 was solved to estimate surface $\mathrm{pH}$ which was found to be 10.02

$j=\frac{F}{\delta} *\left[D_{H}^{+} *\left(C_{H}^{+s}-C_{H}^{+b}\right)-D_{O H}^{-H} * K_{O W} *\left(\frac{1}{C_{H}^{+s}}-\frac{1}{C_{H}^{+b}}\right)\right] \quad$ Equation S15

Here, $j$ signifies current density, $D_{H}^{+}$is proton diffusion coefficient, $C_{H}^{+s}$ is the surface proton concentration to be calculated, $C_{H}^{+b}$ is the bulk proton concentration, $D_{\overline{O H}}$ is the diffusion coefficient of the hydroxide ion, $K_{O W}$ is the ionic product of water, $\mathrm{F}$ is Faraday's constant and $\delta$ is the boundary layer thickness.
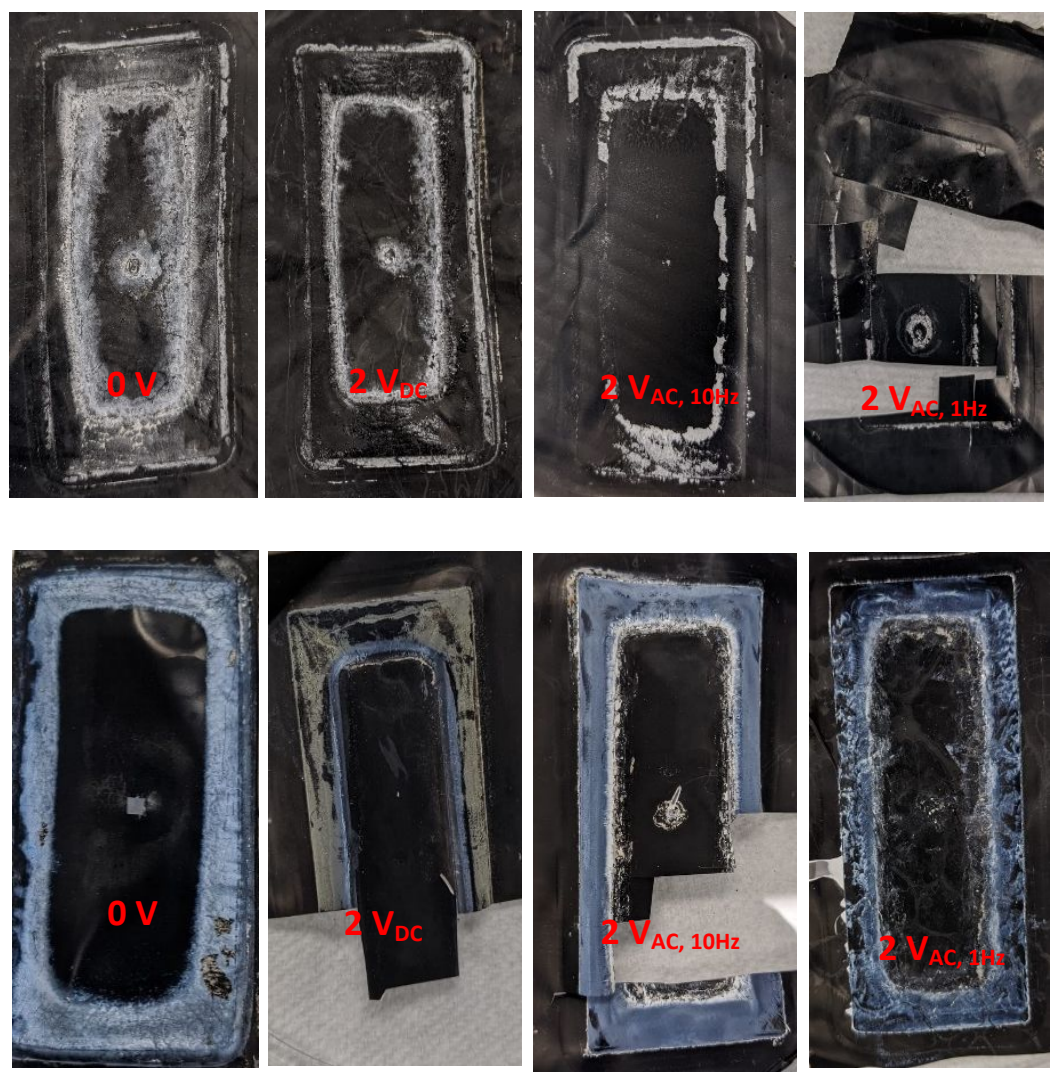

Figure S4. Pictures of the (a) $\mathrm{CaSO}_{4}$ and (b) silicate scaled membranes under different operating conditions 


\section{Calculating EDL thickness}

EDL thickness was calculated by using equation S16

$\lambda_{D}=\left(\frac{\varepsilon k_{B} T}{e^{2} \sum n_{i} z_{i}^{i}}\right)^{0.5}$

Equation S16

Where, $\lambda_{D}$ is the Debye length which is a measure of EDL thickness, $\varepsilon, \mathrm{k}_{B}$, and $T$ are the permittivity, Boltzmann constant and temperature respectively, $e$ is the charge on one electron, $n_{i}$ and $z_{i}$ are the ionic concentration and charge of individual ions in the solution.
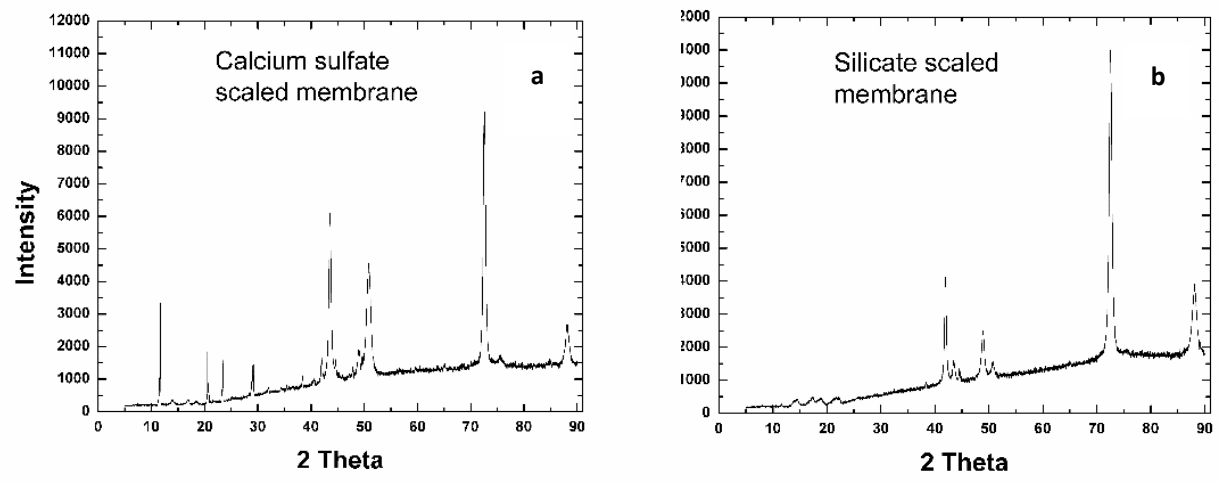

Figure S5. X-ray diffractogram of the (a) $\mathrm{CaSO}_{4}$ and (b) silicate scaled membranes.
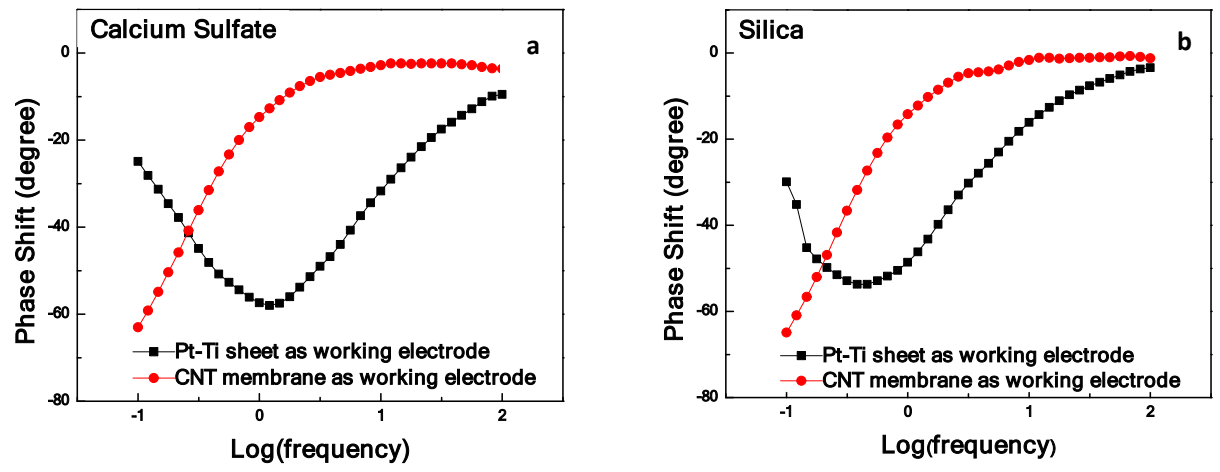

Figure S6. Phase shift versus frequency with a highly conductive metal plate (Pt-Ti) as the working electrode (black) and CNT membrane as the working electrode (red) for (a) $\mathrm{CaSO}_{4}$, and (b) silicate solution. 


\section{Economic analysis}

The proposed ECMD system has the potential to enhance membrane lifetime (by scaling mitigation), reduce membrane cleaning frequency, minimize pretreatment requirements, and reduce the volume of brine that requires disposal (by enhancing water recovery). The additional costs of this process (over conventional MD processes) are associated with fabricating the conductive CNT/PVA composite (cost of materials and fabrication), and energy requirements for the application of the electrical potential. In this section, we consider only the additional capital and operating costs incurred, and potential savings offered, by our process, without considering costs associated with membrane system design, heating of the feed solution, or pumping and cooling of the permeate stream, as these are expected to be comparable with conventional MD processes.

The cost of $\mathrm{COOH}$-functionalized multi-wall CNTs used here is $\$ 0.6 \mathrm{~g}^{-1}$. A single piece of membrane being coated $\left(16 \mathrm{~cm} \mathrm{X} 30 \mathrm{~cm}\right.$ or $\left.0.048 \mathrm{~m}^{2}\right)$ requires $0.2 \mathrm{~g}\left(200 \mathrm{ml}\right.$ of $1 \mathrm{~g} \mathrm{~L}^{-1} \mathrm{CNT}$ solution), resulting in a requirement of $4.17 \mathrm{~g} \mathrm{CNT} \mathrm{m}^{-2}$, which translates to a cost of $\$ 2.5 \mathrm{~m}^{-2}$. A mathematical model for the design and fabrication of polymer solar cells by spray coating has been used to estimate the thermal cost of spray coating a CNT solution on to the membrane. ${ }^{[69]}$ With an assumed substrate speed of $0.15 \mathrm{~m} \mathrm{~s}^{-1}$ and a nozzle-substrate distance of $0.3 \mathrm{~m}$, for a $1 \mathrm{~g} \mathrm{~L}^{-1}$ solution of CNT, the thermal cost of spray coating (which dominates over other electric costs) was $\$ 2 \mathrm{~m}^{-2}$ per layer. The total additional cost of membrane fabrication is therefore $\$ 2+\$ 2.5=\$ 4.5 \mathrm{~m}^{-2}$. Assuming a flux of $30 \mathrm{LMH}$ and an operation time of 20 hours a day and 360 days a year, the water treated over this five-year period is $1080 \mathrm{~m}^{3} \mathrm{~m}^{-2}$. This results in an additional cost of $\$ 0.004 \mathrm{~m}^{-3}$.

The power required to apply $2 \mathrm{~V}_{\mathrm{AC}, 1 \mathrm{~Hz}}$ was calculated using Equation $2:[70]$

$P=\frac{V^{\wedge} 2}{Z} \cos \theta$ 
where $\mathrm{V}$ is the voltage applied $(2 \mathrm{~V}), \mathrm{Z}$ is the impedance measured from EIS data and $\theta$ is the phase shift. The impedance of the system was determined to be $191 \Omega$ for the $\mathrm{CaSO}_{4}$ solution and $182 \Omega$ for the silicate solution. Using Equation 2, it was determined that the power requirements were $0.02 \mathrm{~W}$ for both solutions (for the $0.004 \mathrm{~m}^{2}$ piece of membrane). This results in a power requirement of $5 \mathrm{~W} \mathrm{~m}^{-2}$. Over the five-year period being considered, power requirements are $180 \mathrm{kWh} \mathrm{m}^{-2}$. Assuming electricity to cost $\$ 0.12$ per $\mathrm{kWh}$, the resulting cost is $\$ 21.6$ per $\mathrm{m}^{2}$, which for $1080 \mathrm{~m}^{3}$ of treated water results in $\$ 0.02$ per $\mathrm{m}^{3}$. Thus, the total additional costs incurred are $\$ 0.004$ per $\mathrm{m}^{3}$ (membrane fabrication) $+\$ 0.02$ per $\mathrm{m}^{3}$ (electrical potential applied) $=\$ 0.024$ per $\mathrm{m}^{3}$ water produced. In terms of savings, these costs need to be compared to the cost of anti-scalants and brine disposal, which vary depending on the physical location and the chemical composition of the water requiring treatment.

\section{References}

[1] L. Martínez-Díez, M. I. Vazquez-Gonzalez, Journal of membrane science 1999, 156, 265. 